\title{
Symptom Interference with Life Likert Scale
}

National Cancer Institute

\section{Source}

National Cancer Institute. Symptom Interference with Life Likert Scale. NCI Thesaurus.

Code C120085.

A scale for the subjective scoring of a symptom's interference with life that ranges from

0: Did Not Interfere to 10: Interfered Completely. 